\title{
Oxalates as Activating Groups for Alcohols in Visible Light Photoredox Catalysis: Formation of Quaternary Centers by Redox-Neutral Fragment Coupling
}

\author{
Christopher C. Nawrat ${ }^{\# \dagger}$, Christopher R. Jamison ${ }^{\# \ddagger}$, Yuriy Slutskyy $\# \ddagger$, David W. C. \\ MacMillan ${ }^{*}$, , and Larry E. Overman ${ }^{*}, \ddagger$ \\ †Merck Center for Catalysis at Princeton University, Princeton, New Jersey 08544, United States \\ ‡Department of Chemistry, University of California, Irvine, California 92697-2025, United States \\ \# These authors contributed equally to this work.
}

\begin{abstract}
Alkyl oxalates are new bench-stable alcohol-activating groups for radical generation under visible light photoredox conditions. Using these precursors, the first net redox-neutral coupling of tertiary and secondary alcohols with electron-deficient alkenes is achieved.
\end{abstract}

\begin{abstract}
Nucleophilic tertiary carbon radicals are useful intermediates for combining structurally complex carbon fragments with the formation of new quaternary carbons. ${ }^{1}$ These alkyl radicals are formed most commonly from halide precursors; however, competing elimination and rearrangement reactions can under-mine the preparation of structurally complex tertiary halides. ${ }^{2}$ In contrast, tertiary alcohols would be ideal precursors of tertiary radicals because they can be prepared by various reliable methods and are widely commercially available. Inspired by Barton's introduction of tert-alkyl $\mathrm{N}$ hydroxypyridine-2-thionyl oxalates for generating carbon radicals from alcohols, ${ }^{2 b}$ Overman et al. recently introduced $N$-phthalimidoyl oxalate derivatives of tertiary alcohols for the reductive coupling of tertiary radicals with Michael acceptors using visible light and $\left[\mathrm{Ru}(\mathrm{bpy})_{3}\right]\left(\mathrm{PF}_{6}\right)_{2}($ eq 1$) .{ }^{3-5}$ Though this method was shown to possess a wide substrate scope, its mechanism necessitates the use of a stoichiometric reductant to produce the tertiary alkyl radical and forms phthalimide as a byproduct. Also, the inherent
\end{abstract}

\footnotetext{
*Corresponding Authorsdmacmill@princeton.edu, leoverma@uci.edu. Supporting Information

The Supporting Information is available free of charge on the ACS Publications website at DOI: 10.1021/jacs.5b07678. Experimental procedures and data. (PDF)

Notes

The authors declare no competing financial interest.
} 

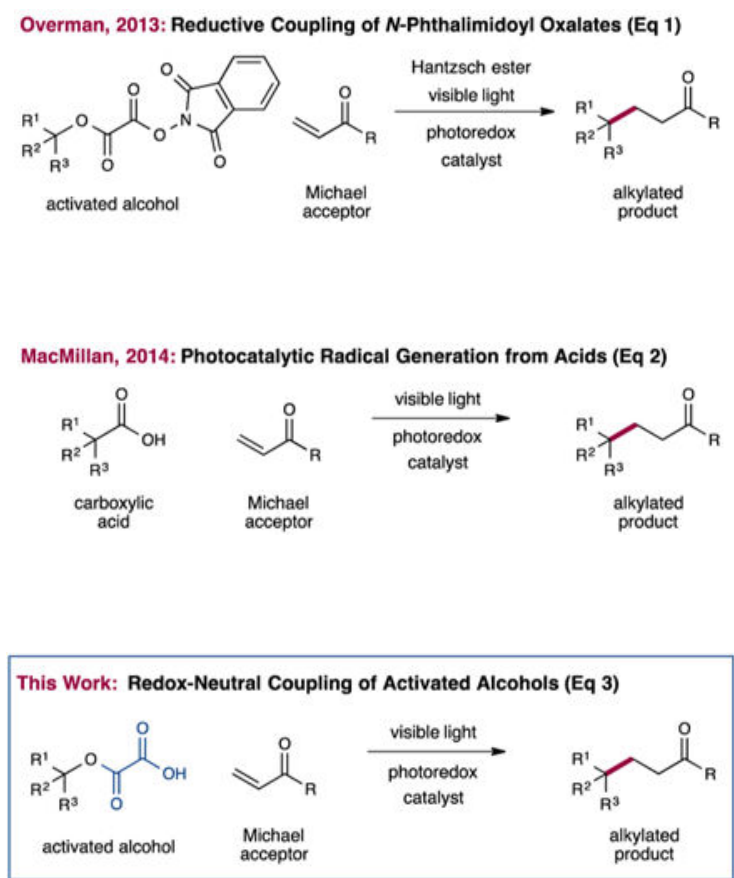

sensitivity of the $N$-phthalimidoyl oxalate moiety can present complications for purification of the requisite intermediates because $\mathrm{N}$-phthalimidoyl oxalates are not stable to aqueous workup or flash chromatography. As such, identifying an activating group for tertiary alcohols that is both stable and capable of generating and coupling radicals in a redoxneutral fashion (i.e., without the need for supplementary reductants or oxidants) would be a desirable goal. The MacMillan group reported a net redox-neutral method to generate carbon radicals and couple them with Michael acceptors by visible-light-promoted decarboxylation of carboxylic acids using the photo-catalyst $\operatorname{Ir}\left[\mathrm{dF}\left(\mathrm{CF}_{3}\right) \mathrm{ppy}\right]_{2}(\mathrm{dtbbpy}) \mathrm{PF}_{6}(1)$ (eq 2). ${ }^{6} \mathrm{In}$ contrast to the reductive coupling of $\mathrm{N}$-phthalimidoyl oxalates, this method produces no byproduct other than $\mathrm{CO}_{2}$. We questioned whether it would be possible to combine the salient features of both the Overman and MacMillan radical generation methods to identify a new activating-group strategy for tertiary alcohols that proceeds via a redox-neutral manifold using stable, easily handled intermediates. Here we report that simple oxalate salts of tertiary alcohols undergo high-yield photocatalytic coupling with electro-deficient alkenes in the presence of 1 and visible light (eq 3).

The mechanistic details of the proposed coupling reaction are outlined in Scheme 1. Irradiation of heteroleptic photocatalyst $\operatorname{Ir}\left[\mathrm{dF}\left(\mathrm{CF}_{3}\right) \text { ppy }\right]_{2}(\mathrm{dtbbpy}) \mathrm{PF}_{6}(\mathbf{1})\left[\mathrm{dF}_{(\mathrm{CF}}\right)$ ppy $=2$ (2,4-difluorophenyl)-5-trifluoromethylpyridine, dtbbpy $=4,4^{\prime}$-di-t-Bu-2,2'-bipyridine] with visible light leads to the formation of a long-lived $(\tau=2.3 \mu \mathrm{s})$ excited state $* \mathrm{Ir}^{\mathrm{III}} \mathbf{2}$, which is a strong oxidant $\left(E^{1 / 2 \text { red }}\left[* \mathrm{Ir}^{\mathrm{III}} / \mathrm{II}^{\mathrm{II}}\right]=+1.21 \mathrm{~V}\right.$ vs SCE in $\left.\mathrm{CH}_{3} \mathrm{CN}\right) .{ }^{7}$ On the basis of this, we hypothesized that oxidation of the conjugate base of $\mathbf{3}\left(E^{1 / 2 \mathrm{red}}=+1.28 \mathrm{~V}\right.$ vs SCE in $\mathrm{CH}_{3} \mathrm{CN}$ for $t$-BuOCOCO$\left.{ }_{2} \mathrm{Cs}\right)^{8}$ by $* \mathrm{Ir}^{\mathrm{III}}$ (2) via single-electron transfer (SET) should be thermodynamically feasible, generating $\mathbf{4}$ following the stepwise loss of two molecules of $\mathrm{CO}_{2}{ }^{2 \mathrm{~b}, 3 \mathrm{a}}$ Nucleophilic C-centered radical $\mathbf{4}$ should rapidly undergo addition to electro- 
deficient alkenes such as $\mathbf{5}$. Finally, we red expected that reduction of resulting adduct radical $6\left(E_{1 / 2 \text { red }}=-0.59 \text { to }-0.73 \mathrm{~V} \text { vs SCE in } \mathrm{MeCN}\right)^{9}$ by SET from available Ir ${ }^{\mathrm{II}}$ species $3\left(E_{1 / 2 \text { red }}\left[\mathrm{Ir}^{\mathrm{III}} / \mathrm{II}^{\mathrm{II}}\right]=-1.37 \mathrm{~V} \text { vs SCE in } \mathrm{CH}_{3} \mathrm{CN}\right)^{7}$ should yield 7 after protonation and regenerate ground-state photocatalyst $\mathbf{1}$, completing the proposed catalytic cycle.

We first explored the proposed decarboxylative alkylation reaction using the alkyl hydrogenoxalate derived from 1-methyl-1-cyclohexanol as the radical precursor in the presence of benzyl acrylate as an archetypal Michael acceptor (Table 1). Using 1 as photocatalyst and dipotassium phosphate as base, ${ }^{6}$ we were delighted to obtain the desired product in moderate yield (entry 1). Further optimization revealed $\mathrm{CsF}$ to be a more competent base and a 3:1 mixture of DME/DMF to be the optimal solvent (entries 2-4).

Though tert-alkyl hydrogen oxalates clearly function as viable radical precursors, many were observed to be intrinsically unstable species that disproportionate into a mixture of the corresponding dialkyl oxalate and oxalic acid, even during storage at $-18{ }^{\circ} \mathrm{C} .{ }^{10}$ Also, it was apparent that the presence of a highly acidic hydrogen oxalate would likely preclude the preparation of substrates containing sensitive functional groups. Fortunately, it was found that the preformed Cs salts of the starting acids were also competent in the reaction (entry 5). In contrast to the parent acid (and, indeed, to most activating groups for tertiary alcohols used for radical generation), ${ }^{2,3}$ alkyl cesium oxalates were bench-stable, nonhygroscopic, and easy to isolate and handle. ${ }^{11}$ Adding 10 equiv of water was found to be beneficial when utilizing the preformed oxalate salt, giving the coupled product in an excellent 95\% yield (entry 6). Presumably, water both assists in solubilizing oxalate salt and provides a proton source to quench the intermediate cesium enolate after radical coupling and reduction. Additionally, oxalates bearing other alkali counterions, such as Li (entry 7), performed comparably to cesium oxalates in the reaction. ${ }^{12}$ The use of a $26 \mathrm{~W}$ CFL bulb in place of a $34 \mathrm{~W}$ blue LED lamp resulted in a diminished but still useful yield (entry 8). Finally, it was observed that control experiments run in the absence of photocatalyst or a visible light source did not generate any of the desired 1,4-addition product (entries 9 and 10).

Having identified optimal conditions, we examined the scope of the acceptor component. As shown in Table 2, a wide range of electro-deficient alkenes can be used in the reaction. As expected, various acrylates were capable acceptors in the reaction (10 and 11, 88 and 86\% yield, respectively); the presence of $a$ substitution was well-tolerated (17--20, 85-96\% yield). Also, $\alpha, \beta$-unsaturated acids can be used as coupling partners, owing to the low basicity of the oxalate salt $(\mathbf{2 0}, 85 \%$ yield). This procedure could be applied to a range of other electro-deficient alkenes (e.g., enones, enals, acrylamides, vinyl phosphonates, and vinyl sulfones; 12-16, 68-86\% yield). Surprisingly, acrylonitrile produced little product (11\% yield), ${ }^{13}$ whereas methacrylonitrile proved to be a much more capable acceptor $(\mathbf{1 7}$, $85 \%$ yield). Substitution at the $\beta$ position was tolerated for more electro-deficient alkenes such as dimethyl fumarate and dimethyl ethylidene- and benzylidenemalonate, furnishing the expected adducts with good efficiency (21-23, 70-99\% yield). As expected, 4vinylfura-2-one gave exclusively the 1,6-addition product in excellent yield (24, 89\% yield). In the case of acceptors harboring existing stereogeniccenters, high levels of diastereoselectivity were obtained ( 25 and $\mathbf{2 6}, \mathbf{7 3 - 9 0 \% ~ y i e l d , ~ > ~ 2 0 : 1 ~ d r ) . ~}$ 
Next, we investigated the scope of cesium oxalate (Table 3). Owing to the long forming bond (2.2-2.5 $\AA$ ) in the transition state of carbon radical conjugate addition ${ }^{14}$ and the poor solvation of carbon radicals, ${ }^{1 \mathrm{~b}}$ the reaction proved quite insensitive to steric hindrance around the site of radical generation, with adjacent isopropyl and tert-butyl groups not greatly reducing the efficiency of the reaction (29 and 31, 73- 93\% yield). Cyclopentanolderived oxalates also underwent coupling in good yield ( 33 and 39, 85-92\% yield), but very low conversion was observed for 1-methylcyclopropanol- and 1-methylcyclobutanol-derived oxalates. Heterocycles (e.g., pyrro-lidines, piperidines, tetrahydrofurans, pyridines, and indoles) were well-tolerated in the reaction (35, 37, 41,59, and 63, 54- 77\% yield).

Underscoring the utility of this method for constructing quaternary stereocenters in complex molecules, natural product-derived oxalates also performed well, with good levels of diastereoselectivity being observed (41, 43, 45, 47, and 49, 85-96\% yield). Indeed, high yields were obtained even for the formation of vicinal quaternary stereocenters $(\mathbf{4 7}, 85 \%$ yield). Also, a number of acyclic tert-alkyl oxalates also undergo the coupling with high levels of efficiency $(\mathbf{5 1 - 6 3}, 54-93 \%$ yield).

The reaction was examined with several secondary cesium oxalates; two representative examples are shown in Table 4. Although still synthetically useful, lower yields of coupled products were obtained with these substrates, and the product of trapping of the intermediate alkoxyacyl radical was also isolated ( $\mathbf{6 5}$ and $\mathbf{6 6}$ ). For more stabilized benzylic radicals, these side products were not observed; the yields remained moderate $(\mathbf{6 8})$.

The reaction also enabled a short synthesis of $\mathbf{7 0},{ }^{15}$ a member of the trans-clerodane family of natural products (Scheme 2). ${ }^{16}$ Activation of the tertiary alcohol of known intermediate $\mathbf{6 9}^{17}$ is particularly challenging because the trans-decalin ring system places the tertiary alcohol in a 1,3-diaxial relationship with the angular methyl substituent. This severe steric interaction had previously prevented the preparation of the $N$-phthalimidoyl oxalate derivative. ${ }^{17}$ However, acylation of $\mathbf{6 9}$ with methyl chlorooxoacetate proceeded in excellent yield. In situ hydrolysis with aqueous $\mathrm{CsOH}$ allowed pure cesium oxalate $\mathbf{4 4}$ tobe isolated in one step and high yield from alcohol 69 without the use of chromatography. Coupling of oxalate 44 (1.5 equiv) with commercially available 4-vinylfura $N$-2-one (1.0 equiv) proceeded with perfect diastereo- and regioselectivity in $98 \%$ yield to give trans-clerodane 70, a natural product that is a versatile precursor of many other members of the transclerodane family. ${ }^{17}$

We have developed a new visible light photoredox-catalyzed method for the generation of alkyl radicals from secondary and tertiary alcohols and shown its use in the redox-neutral formation of quaternary carbon centers through alkylation with electron deficient alkenes. The intermediate alkyl cesium oxalates are bench-stable, easily handled, and provide a notably convenient means to activate alcohols for radical generation.

\section{Supplementary Material}

Refer to Web version on PubMed Central for supplementary material. 


\section{ACKNOWLEDGMENTS}

Financial support at UC Irvine was provided by the NSF (CHE1265964) and the NIHGMS (R01-GM098601) and at Princeton by the NIHGMS (R01-GM078201).

\section{REFERENCES}

1. (a) Giese B. Angew. Chem., Int. Ed. Engl. 1983; 22:753.(b) Barton DHR, Sas W. Tetrahedron. 1990; 46:3419.(c) Russell GA, Shi BZ, Jiang W, Hu S, Kim BH, Baik W. J. Am. Chem. Soc. 1995; 117:3952.(d) Togo H, Taguchi R, Yamaguchi K, Yokoyama M. J. Chem.Soc., Perkin Trans. 1995; 1:2135.(e) Schnermann MJ, Overman LE. Angew. Chem., Int. Ed. 2012; 51:9576.(f) Lo JC, Yabe Y, Baran PS. J. Am. Chem. Soc. 2014; 136:1304. [PubMed: 24428607]

2. (a) Dolan SC, MacMillan JJ. Chem. Soc., Chem. Commun. 1985:1588. In addition to halides, a number of activating groups have been reported that allow tertiary alcohols to be used as radical precursors. For existing methods that employ oxalate or xanthate derivatives, see. (b) Barton DHR, Crich DJ. Chem. Soc., Perkin Trans. 1986; 1:1603.(c) Coppa F, Fontana F, Lazzarini E, Minisci F, Pianese G, Zhao L. Chem. Lett. 1992:1295.(d) Crich D, Fortt SM. Synthesis. 1987; 1987:35.(e) Coppa F, Fontana F, Lazzarini E, Minisci F. Chem. Lett. 1992:1299.(f) Togo H, Matsubayashi S, Yamazaki O, Yokoyama M. J. Org. Chem. 2000; 65:2816. [PubMed: 10808463]

3. (a) Lackner GL, Quasdorf KW, Overman LE. J. Am. Chem. Soc. 2013; 135:15342. [PubMed: 24074152] (b) Lackner GL, Quasdorf KW, Pratsch G, Overman LE. J. Org. Chem. 2015; 80:6012. [PubMed: 26030387]

4. (a) Tucker JW, Stephenson CRJ. J. Org. Chem. 2012; 77:1617. For recent reviews on photoredox catalysis, see. [PubMed: 22283525] (b) Prier CK, Rankic DA, MacMillan DWC. Chem. Rev. 2013; 113:5322. [PubMed: 23509883] (c) Xie J, Jin H, Xu P, Zhu C. Tetrahedron Lett. 2014; 55:36.(d) Schultz DM, Yoon TP. Science. 2014; 343:1239176. [PubMed: 24578578]

5. (a) Renaud P, Gerster M. Angew. Chem., Int. Ed. 1998; 37:2562. For selected reviews on radical conjugate additions in general, see. (b) Sibi MP, Porter NA. Acc. Chem. Res. 1999; 32:163.(c) Sibi MP, Manyem S, Zimmerman J. Chem. Rev. 2003; 103:3263. [PubMed: 12914498] (d) Srikanth GSC, Castle SL. Tetrahedron. 2005; 61:10377.

6. Chu L, Ohta C, Zuo Z, MacMillan DWC. J. Am. Chem. Soc. 2014; 136:10886. [PubMed: 25032785]

7. Lowry MS, Goldsmith JL, Slinker JD, Rohl R, Pascal RA, Malliaras GG, Bernhard S. Chem. Mater. 2005; 17:5712.

8. See the Supporting Information for further details about CV measurements

9. (a) Bortolamei N, Isse AA, Gennaro A. Electrochim. Acta. 2010; 55:8312.(b) See the Supporting Information for evidence of an enolate intermediate.

10. This disproportionation is unique to tert-alkyl hydrogen oxalates. Alkyl hydrogen oxalates derived from primary and secondary alcohols are stable and do not readily disproportionate

11. The cesium oxalates were most conveniently prepared via hydrolysis of the corresponding tertalkyl methyl oxalates with aqueous $\mathrm{CsOH}$. This route avoids the potentially unstable alkyl hydrogen oxalatemoiety; the tert-alkyl methyl oxalate intermediates are stable to silica column chromatography and aqueous work up. The cesium oxalates may also be prepared in a simple onepot procedure directly from tertiary alcohols (Supporting Information)

12. Lithium, sodium, potassium, and cesium oxalates all gave similar results (Supporting Information). However, cesium oxalates were chosen for development under the assumption that they were likely to have favorable physical properties over a wide range of oxalate substrates.

13. Rapid reaction of the coupled radical with additional acrylonitrile is likely responsible for the low yield in this case

14. (a) Damm W, Giese B, Hartung J, Hasskerl T, Houk KN, Hueter, Zipse H. J. Am. Chem. Soc. 1992; 114:4067.(b) Arnaud R, Postlethwaite H, Barone V. J. Phys. Chem. 1994; 98:5913.

15. Hara N, Asaki H, Fujimoto Y, Gupta Y, Singh A, Sahai M. Phytochemistry. 1995; 38:189.

16. (a) Merritt AT, Ley SV. Nat. Prod. Rep. 1992; 9:243. For general information on the clerodane terpenoids, see. [PubMed: 1436738] (b) Tokoroyama T. Synthesis. 2000; 2000:611. 
17. Müller DS, Untiedt NL, Dieskau AP, Lackner GL, Overman LE. J. Am. Chem. Soc. 2015; 137:660. [PubMed: 25563555] 


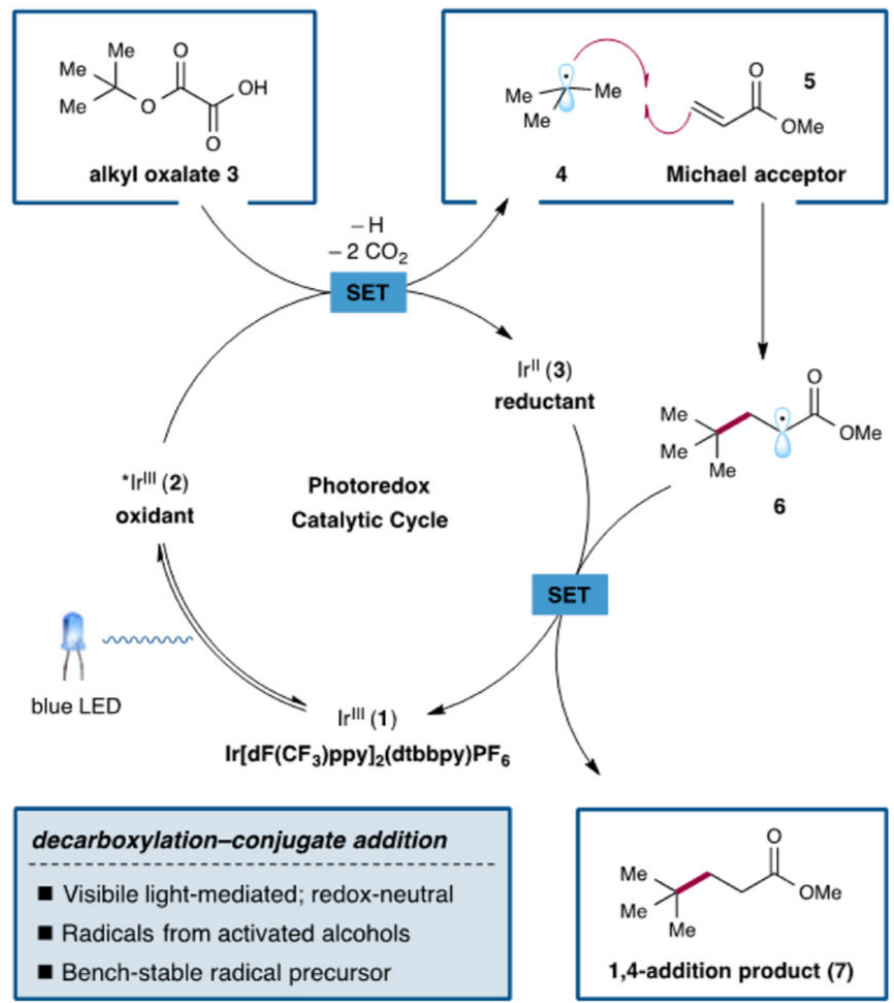

Scheme 1.

Proposed Mechanism for Redox-Neutral Radical-Coupling Reaction Using Alkyl Oxalates and Michael Acceptors 


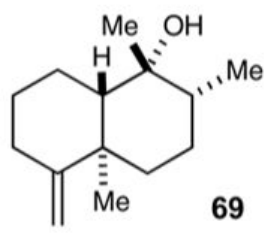

known alcohol (4-steps)

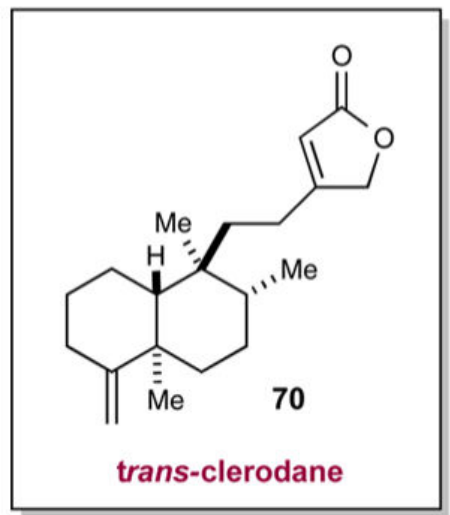

$n$-BuLi, THF, $-78^{\circ} \mathrm{C}$ then $\mathrm{ClCOCO}_{2} \mathrm{Me}$

then $\mathrm{CsOH}(\mathrm{aq})$ one-pot, $93 \%$ yield<smiles>C1CCC1</smiles><smiles>C=C1CCC[C@@]2(C)C(O)(O)[C@H](C)CC[C@]12C</smiles><smiles>C=CC1=CC(=O)OC1</smiles>

$1 \mathrm{~mol} \%$ photocatalyst 1 3:1 DME:DMF, $\mathrm{H}_{2} \mathrm{O}, 40^{\circ} \mathrm{C}$

$34 \mathrm{~W}$ Blue LEDS

$98 \%$ yield, $>20: 1 \mathrm{dr},>20: 1 \mathrm{rr}$

Scheme 2.

Six-Step Synthesis of a trans-Clerodane Natural Product 


\section{Table 1}

Initial Studies and Reaction Optimization

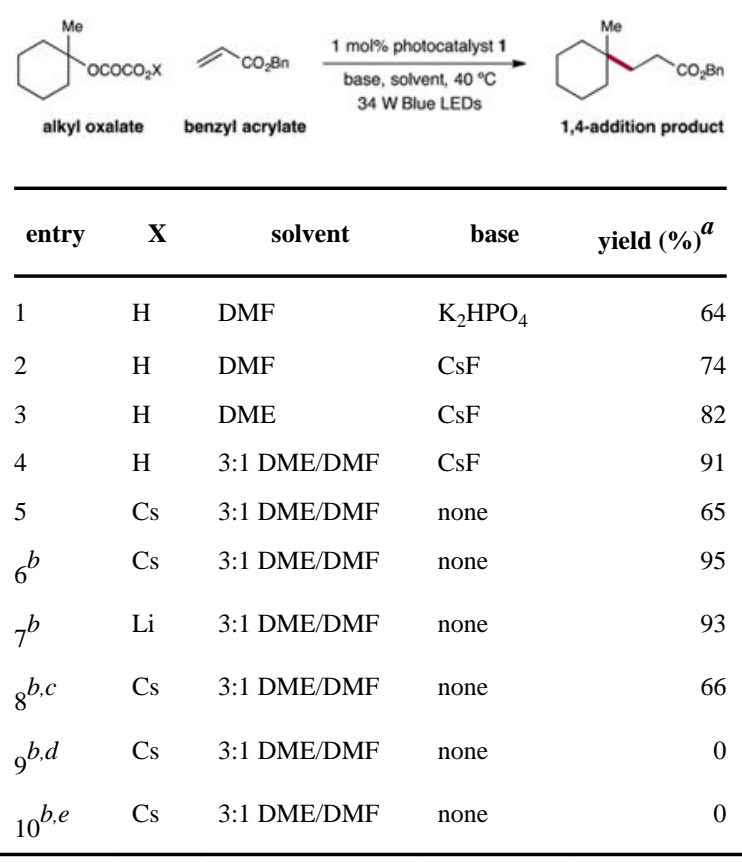

${ }^{a}$ Reactions on a $0.2 \mathrm{mmol}$ scale using 1.0 equiv of acceptor and 1.1 equiv of oxalate. Yields determined by ${ }^{1} \mathrm{H}$ NMR using mesitylene as an internal standard.

$b_{\text {Water added }}=10$ equiv.

${ }^{c}$ Reaction carried out with $26 \mathrm{~W}$ CFL.

$d_{\text {Reaction carried out without photocatalyst. }}$

${ }^{e}$ Reaction carried out in the absence of light. 
Table 2

Acceptor Scope with Alkyl Cesium Oxalate $9^{a}$

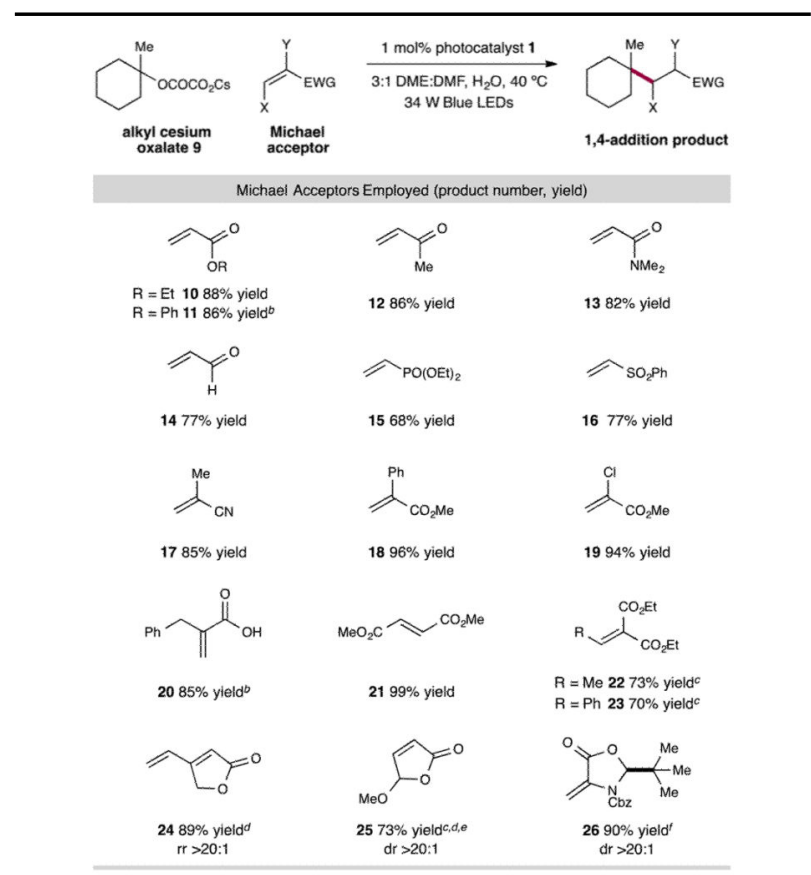

${ }^{a}$ Isolated yields using optimized conditions from Table 1 with 1.0 equiv of acceptor and 1.1 equiv of oxalate (Supporting Information). ${ }^{b}$ Carried out with 1.5 equiv of cesium oxalate. ${ }^{c}$ Carried out in $100 \%$ DME. ${ }^{d}$ Run at $22{ }^{\circ} \mathrm{C}$. ${ }^{e}$ Isolated as trans isomer. ${ }^{f}$ Isolated as cis isomer. 
Table 3

Scope of Cesium Oxalate Salts with Benzyl Acrylate as the Acceptor ${ }^{a}$

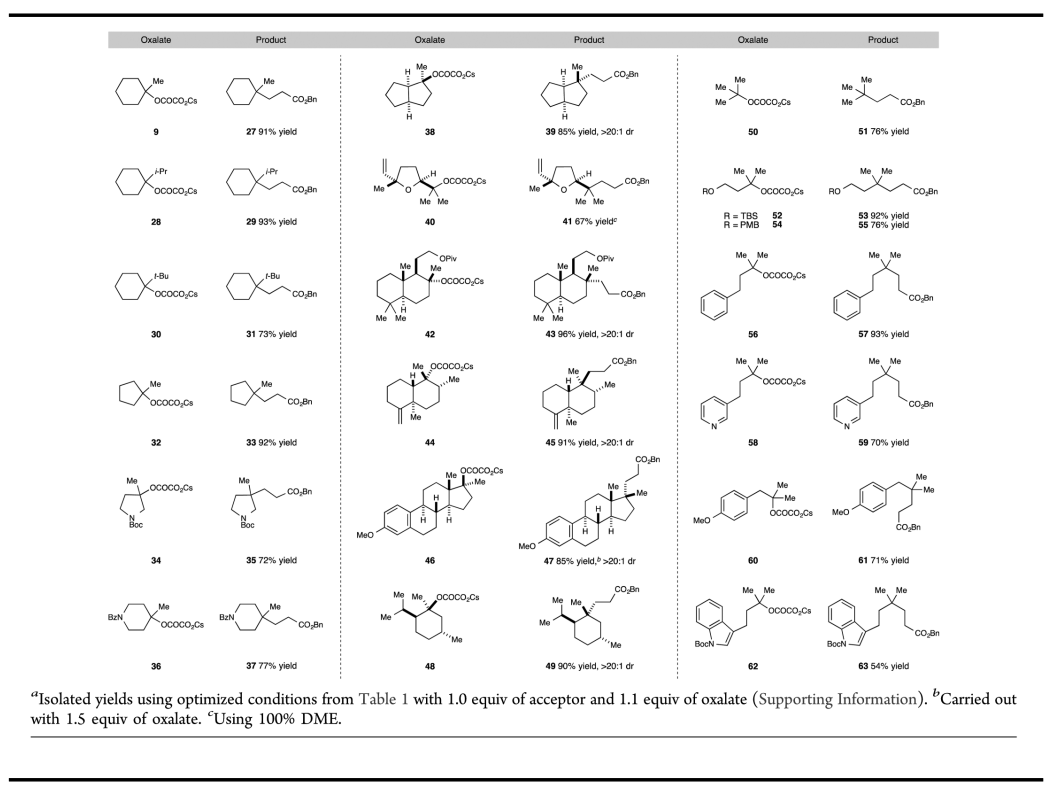

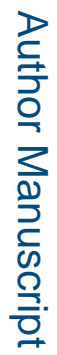

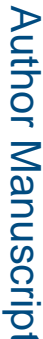
with 1.5 equiv of oxalate. "Using $100 \%$ DME.

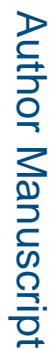

$J$ Am Chem Soc. Author manuscript; available in PMC 2015 November 04. 


\section{Table 4}

Examples of Secondary Oxalate Salts ${ }^{a}$

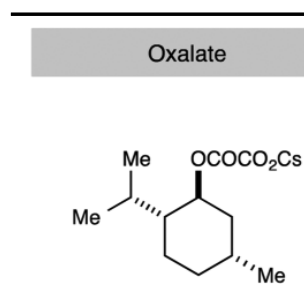

64

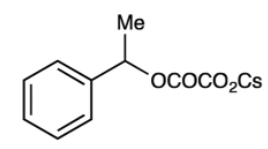

67<smiles>CC(C)[C@H]1CC[C@@H](C)C[C@H]1CCC(=O)OCc1ccccc1</smiles>

$6551 \%$ yield

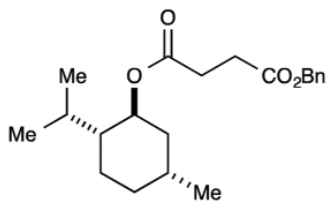

$6629 \%$ yield

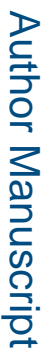

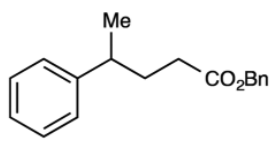

$6857 \%$ yield 